\section{MOLECULAR SECONDARY ION MASS SPECTRA OF KANAMYCINS}

Sir:

In our laboratories two strategies for obtaining mass spectra of involatile and/or thermally unstable natural products have been used. One is an optimization of sample vaporization, which involves rapid sample heating followed by thermal desorption and ionization under chemical ionization (CI) conditions, that is emitter CI mass spectrometry (emitter CIMS). Recently, we have reported a preliminary study on aminoglycosidic antibiotics, kanamycins, by this technique. ${ }^{1)}$ Another technique is a direct ionization of the sample from a surface. Several techniques such as field desorption (FD), ${ }^{2)}{ }^{252} \mathrm{Cf}$ plasma desorption (PD, fission fragment induced), ${ }^{3)}$ laser desorption (LD) ${ }^{4}$ and secondary ion (SI) mass spectrometry ${ }^{5, \theta)}$ have been devised for this purpose. We adopt molecular SIMS because of its simple operation and good reproducibility. Moreover, it should be emphasized that SIMS does not require heating of the sample for its desorption and ionization. Although several reports on application of SIMS to organic compounds have appeared, no spectra of biologically important naturally occurring products with a mass greater than 350 have hitherto been reported except for our studies. ${ }^{7,8)}$ In this study a preliminary investigation of aminoglycosidic antibiotics has been carried out using kanamycins as typical examples.

A double focusing mass spectrometer from Hitachi (M-80) equipped with an additional electron impact (EI) ion source for producing primary ions $\left(\mathrm{Ar}^{+}\right)$was used in this study. A direct sample inlet probe was modified to support a metal substrate on which samples were loaded..$^{9)}$ Silver was used as the metal substrate and $3 \mathrm{kV}$ was applied for acceleration of secondary ions.

Fig. 1 shows the secondary ion mass spectra of kanamycin $\mathrm{A}(\mathbf{1}), \mathrm{B}(\mathbf{2})$ and $\mathrm{C}(\mathbf{3})$. The three cationized molecular species, protonated molecule, $\mathrm{MH}^{+},(\mathrm{M}+\mathrm{Na})^{+}$and $(\mathrm{M}+\mathrm{Ag})^{+}$, are clearly present in the high mass region and they indicate exactly the molecular weights. In particular, the argentated molecules are most important feature in the mass spectra supported on silver, since Ag-containing ions appear as doublet peaks due to the presence of $\mathrm{Ag}$-isotopes $(107,109)$. The principal fragmentations are considered to be restricted to the cleavage of the glycosidic bonds. The resulting fragment ions are summarized in Fig. 2. The pseudodisaccharide derived ions are observed as protonated

Fig. 1. Secondary ion mass spectra of kanamycin $\mathrm{A}(\mathbf{1}), \mathrm{B}(\mathbf{2})$ and $\mathrm{C}(\mathbf{3})$.

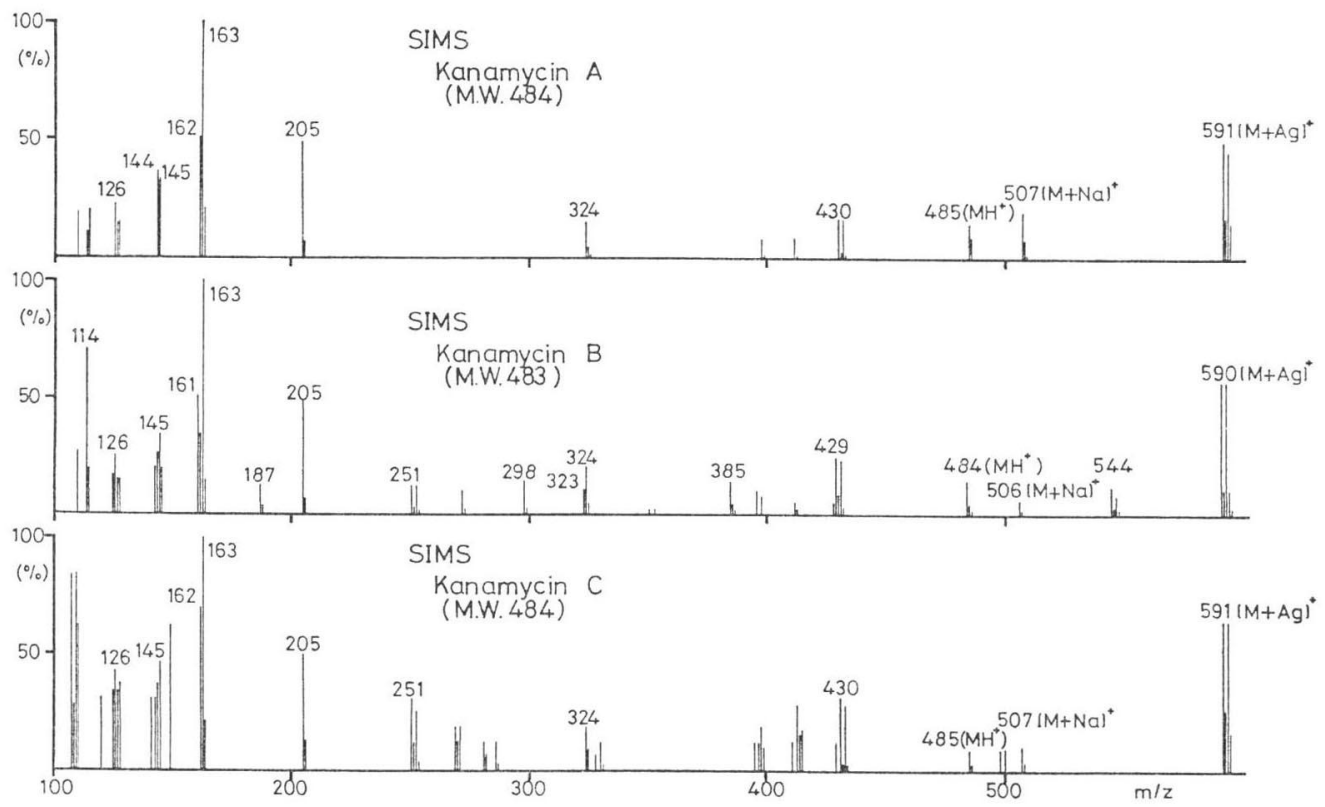


Fig. 2. Major fragmentations and principal ions observed in the secondary ion mass spectra of $\mathbf{1}, \mathbf{2}$ and $\mathbf{3}$.

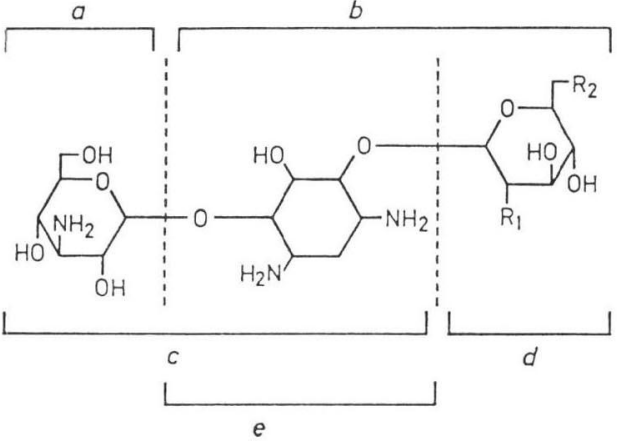

\begin{tabular}{|c|c|c|c|c|c|c|c|c|c|c|}
\hline & $(\mathrm{M}+\mathrm{Ag})^{+}$ & $\frac{(\mathrm{M}+}{\mathrm{Na})^{+}}$ & $\mathrm{MH}^{+}$ & $a^{+}$ & $\begin{array}{l}(b+ \\
2 \mathrm{H})^{+}\end{array}$ & $\begin{array}{l}(c+ \\
2 \mathrm{H})^{+}\end{array}$ & $\underset{(b+\mathrm{H}+}{\mathrm{Ag})^{+}}$ & $\underset{\mathrm{Ag})^{+}}{(c+\mathrm{H}+}$ & $d^{+}$ & $\begin{array}{l}(e+ \\
3 \mathrm{H})^{+}\end{array}$ \\
\hline $\begin{array}{l}\text { Kanamycin A (1) } \\
\mathrm{R}_{1}=\mathrm{OH}, \mathrm{R}_{2}=\mathrm{NH}_{2}\end{array}$ & 591,593 & 507 & 485 & 162 & 324 & 324 & 430,432 & 430,432 & 162 & 163 \\
\hline $\begin{array}{l}\text { Kanamycin B (2) } \\
\mathrm{R}_{1}=\mathrm{NH}_{2}, \\
\mathrm{R}_{2}=\mathrm{NH}_{2}\end{array}$ & 590,592 & 506 & 484 & 162 & 323 & 324 & 429,431 & 430,432 & 161 & 163 \\
\hline $\begin{array}{l}\text { Kanamycin C (3) } \\
\mathrm{R}_{1}=\mathrm{NH}_{2}, \mathrm{R}_{2}=\mathrm{OH}\end{array}$ & 591,593 & 507 & 485 & 162 & 324 & 324 & 430,432 & 430,432 & 162 & 163 \\
\hline
\end{tabular}

Fig. 3. $\mathrm{NaCl}$ co-existing secondary ion mass spectra of 1, 2 and $\mathbf{3}$.

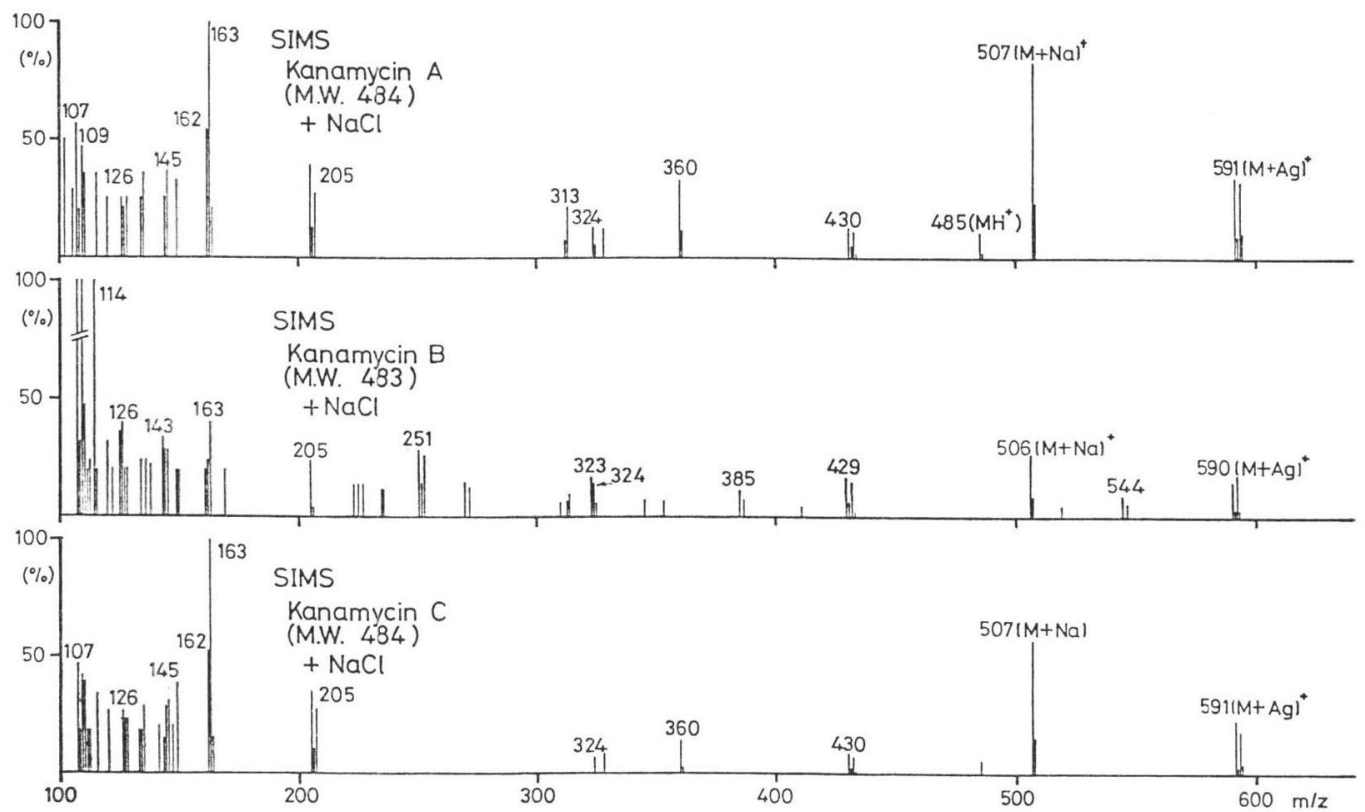

type, $(b \text { or } c+2 \mathrm{H})^{+}$and argentated form, $(b$ or $c+\mathrm{H}+\mathrm{Ag})^{+}$, while the monosaccharide ions $(a$ or $d$ ) are mainly recognized as oxonium type ion. The protonated deoxystreptamine ion $(e+3 \mathrm{H})^{+}$ appears at $m / z 163$ in common with the spectra of 1, 2 and $\mathbf{3}$.
It is well known that the addition of $\mathrm{NaCl}$ is effective for obtaining intense $(\mathrm{M}+\mathrm{Na})^{+}$ions in FD mass spectra. ${ }^{10)}$ The $\mathrm{NaCl}$ co-existing secondary ion mass spectra of $\mathbf{1 , 2}$ and $\mathbf{3}$ are shown in Fig. 3. As anticipated, the relative abundances of $(\mathrm{M}+\mathrm{Na})^{+}$ions increase considerably in all 
Fig. 4. Glycerol matrix-assisted secondary ion mass spectra of 1, 2 and 3.

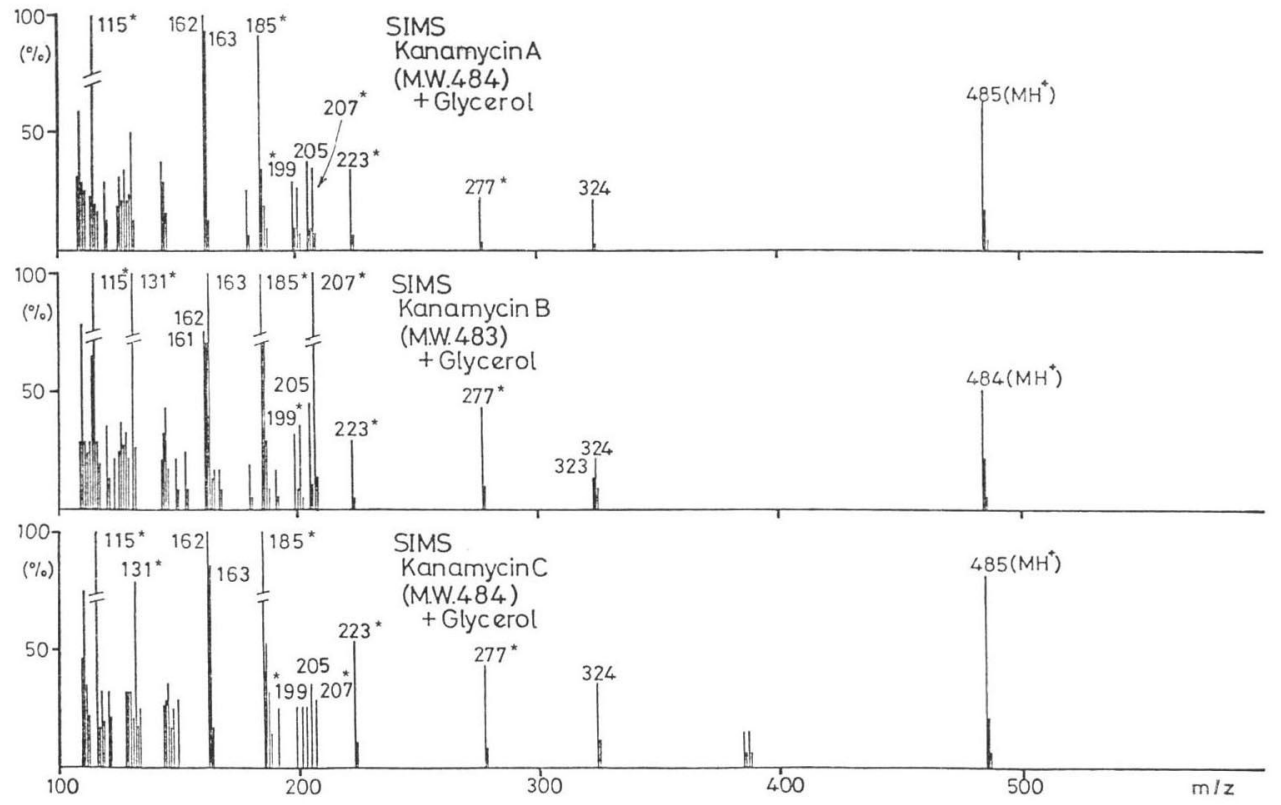

* These ions are derived from glycerol.

the spectra.

Further, the glycerol matrix-assisted secondary ion mass spectra of $\mathbf{1 , 2}$ and $\mathbf{3}$ are presented in Fig. 4. In the molecular ion region, only the $\mathrm{MH}^{+}$ions are observed, however, their basal fragmentations are closely similar to those of the above two cases. That is, the structurally significant sequence ions (pseudodisaccharide, monosaccharide and deoxystreptamine derived ions) appear clearly in the mass spectra. Besides, it is significant that these features are quite similar to the fragmentation patterns obtained under emitter CI condition. ${ }^{1)}$

The results mentioned above suggest that molecular SIMS has considerable potential for structural characterization of involatile and thermally labile compounds. The detailed results of other antibiotics of this class will be reported elsewhere.

\section{KEN-ICHI HARADA \\ Makoto SuzuKI \\ NAOHITO TAKEDA \\ Akira Tatematsu}

Faculty of Pharmacy, Meijo University Tempaku, Nagoya, 468, Japan

\section{Hideki Kambara}

Central Research Laboratory, Hitachi Ltd., Kokubunji, Tokyo, 185, Japan

(Received October 16, 1981)

\section{References}

1) Takeda, N.; M. Umemura, K. I. Harada, M. Suzuki \& A. Tatematsu: Emitter chemical ionization mass spectrometry of kanamycins. J. Antibiotics 34: 617 618, 1981

2) Schulten, H.-R.: Biochemical, medical, and environmental applications of field-ionization and field-desorption mass spectrometry. Int. J. Mass Spectrom. Ion Phys. 32: $97 \sim 283,1979$

3) Macfarlane, R. D. \& D.F. Torgerson: Californium-252 plasma desorption mass spectrometry. Science 191: 920 925, 1976

4) Posthumus, M. A.; P. G. Kistemaker \& H.L.C. MeuzelaAR: Laser desorption-mass spectrometry of polar nonvolatile bioorganic molecules. Anal. Chem. 50: 985 991, 1978

5) Benninghoven, A. \& W. K. Sichtermann: Detection, identification and structural investigation of biologically important compounds by secondary ion mass spectrometry. Anal. Chem. 50: $1180 \sim 1184,1978$

6) DAy, R. J.; S. E. Unger \& R. G. CoOKs: Molecular secondary ion mass spectrometry. Anal. Chem. 52: 557A 572A, 1980 
7) Kambara, H. \& S. Hishida: Secondary ion mass spectra of oligosaccharide. Org. Mass Spectrom. 16: 167 170, 1981

8) Kambara, H.; S. Hishida \& H. Naganawa: Secondary ion mass spectra of oligopeptides. Org. Mass Spectrom. 16: in press, 1981
9) Kambara, H. \& S. Hishida: Secondary ion mass spectra of non-volatile bioorganic compounds. Anal. Chem. 53: in press

10) Röllgen, F. W. \& H.-R. Schulten: Molecular weight determination by cationisation. Org. Mass Spectrom. 10: 660 668, 1975 